\title{
Modelling and Control of Three Phase Switching Synchronous Motor Dedicated to Electric Cars
}

\author{
Souhir Tounsi \\ National School of Electronics and Telecommunications of Sfax, Advanced Electronic Systems for Sustainable Energy Laboratory, Sfax \\ University, Sfax, Tunisia
}

Email address:

souhir.tounsi@enetcom.rnu.tn

Tocite this article:

Souhir Tounsi. Modelling and Control of Three Phase Switching Synchronous Motor Dedicated to Electric Cars. International Journal of Electrical Components and Energy Conversion. Vol. 3, No. 1, 2017, pp. 1-13. doi: 10.11648/j.ijecec.20170301.11

Received: January 16, 2017; Accepted: January 18, 2017; Published: March 2, 2017

\begin{abstract}
In this paper, we present a design and control methodology of an innovated structure of three phases switching synchronous motor. The design process is based on analytical method taking in account of the interactions between the control algorithm and the design program. The control strategy is based on the pulse width modulation technique imposing currents sum of a continuous value and a value having a shape varying in phase opposition with respect to the variation of the inductances. This control technology can greatly reduce vibration of the entire system due to the strong fluctuation of the torque developed by the engine, generally characterizing switching synchronous motors. Subsequently, a systemic design and control program is developed. This program is validated following the implementation and the simulation of the control model in the simulation environment Matlab-Simulink. Simulation results are with good scientific level and encourage subsequently the industrialization of the global system.
\end{abstract}

Keywords: Electric Car, Three Phases Switching Synchronous Motor, Modelling, Vibrations, Sizing, Control

\section{Introduction}

Electric motors dedicated to electric cars motorization, is a current project against the advantages of the electric motors compared to their thermal equivalent engines to knowledge $[1,2]$.

- Reliable production cost.

- Ability to monitor optimizing energy consumption.

- Ease of use.

- Low maintenance costs.

- Reduction of air and noise pollution.

- Ability to use embedded energy sources to address oil crises.

The switching motors have took the relief to other types of electric motors due to their benefit such as the progress in the field of the electronic control area of these types of engines as their advantages over other types of electric motors, especially the low cost of production and of maintenance. However, these engine types have a drawback of a large vibration due to the large variation of the salience of these motor types. In this context, we provide a control strategy for an innovated structure of a three phase's synchronous motor with variable reluctance minimizing vibrations acting on the shapes of the supply currents by pulse width modulation with reduced switching frequency, to reduce the losses in the power converter. This control technique is suitable for a systemic design and modelling program of this structure of three phase's switching synchronous motor $[1,2]$.

In this context, this paper has three main parts to Knowledge:

- Description of systemic design and modelling program of the switching motor.

- Description of the control strategy proposed and its advantage over the state of the art.

- Presentations of components models of the power chain.

- Presentations and descriptions of simulation results.

\section{Sizing and Modelling Program}

\subsection{Motor Structure}

The engine is with three-phase (Figure 1) and with two pairs of poles (four rotor teeth). This structure has one tooth 
per phase. The slots are straight and open leading to a significant reduction of the production cost of this type of engine. The coils are a concentrated type which facilitates the automation process of the insertion of coils in one block. Each winding is formed by one coil around one tooth. The mechanical torque developed by the motor is caused by the variation of the motor saliency along the air gap. The rotor teeth are with low height to minimize the effect of the rotor inertia variation in function of rotor position.

To obtain triangular inductances shifted by an angle equal to $2 . \pi / 3$, we must respect the following rules:

- The angular opening of the stator teeth is equal to the angular opening of the rotor teeth.

- The angular opening of the space among stator teeth is equal to $5 / 3$ of the opening of a stator tooth.

The structure of the studied motor is illustrated in Figure 1.

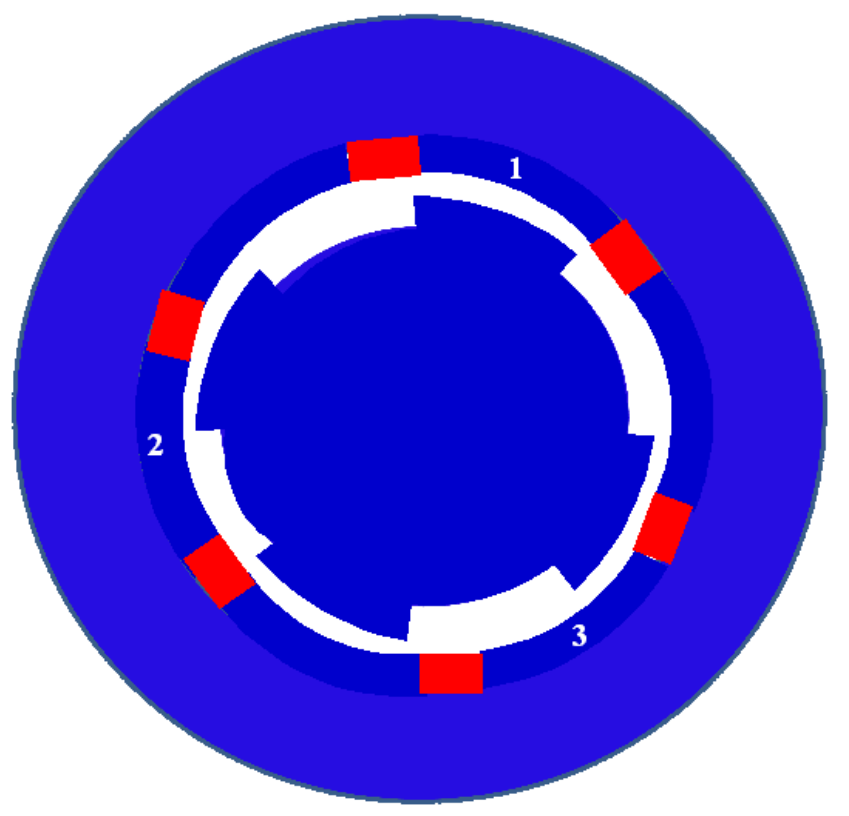

Figure 1. Structure of the switching synchronous motor.

\subsection{Sizing and Modelling Method}

Generally, electrical machinery design problems are solved by the finite element method in two dimensions or three dimensions to have an important accuracy of results. Moreover, this method requires a large simulation time making the resolution of the problems complex and incompatible to optimizations approaches of designed machines performance. In this context, our choice fell on the analytical method to solve the actuator design problem. In addition, this method is the most flexible to vary solutions depending on the power requirement. This method is based on the application of general theorems relating to the design of an electrical device to Knowledge [3-26]:

- Theorem of Ampere.

- Theorem of the Flow conservation.

- Theorem of magnetic fields superposition.

This method is also based on simplifying assumptions justified to knowledge.
- Absolute Permeability of iron is infinite.

- Negligible magnetic field in the iron.

- The magnetic flux loop through the shortest magnetic path.

- Linearity of the B-H characteristic of iron.

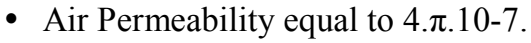

This method is supplemented and adjusted by the finite element method.

\subsection{Configuration Parameters}

The coefficient of the configuration is expressed by the following relation.

$$
C_{c}=\frac{2 \times \pi}{24 \times n}
$$

Where $\mathrm{n}$ is integer. For our case $\mathrm{n}$ is chosen equal to 1 .

The number of stator teeth is expressed by the following relation.

$$
N_{d s}=3 \times n
$$

The number of inserted teeth is expressed by the following relation.

$$
N_{d i s}=3 \times n,
$$

The number of slots is expressed by the following relation.

$$
N_{\text {dis }}=2 \times 3 \times n
$$

The number of rotor tooth is expressed by the following equation.

$$
N_{d r}=4 \times n
$$

The stator phase's tooth angular width is expressed by the following relation.

$$
A_{d s}=3 \times C_{c}
$$

The slot angular width is expressed by the following relation.

$$
A_{s}=C_{c}
$$

The angular width of inserted teeth is expressed by the following relation.

$$
A_{d i s}=3 \times C_{c},
$$

The angular width of the rotor teeth is expressed by the following relation.

$$
A_{d r}=3 \times C_{c}
$$

The opening of the angle between rotor teeth is expressed by the following equation .

$$
A_{e d r}=\frac{2 \times \pi-N_{d r} \times A_{d r}}{N_{d r}},
$$




\subsection{Sizing Parameters}

The magnetic induction in the air-gap is calculated by applying the Ampere Theorem for a maximum flow position in a manner to not satturer iron and have a the lower mass of the engine. This implies that the magnetic induction in the iron must be close to the satturation bend of the iron B-H curve.

$$
B_{e}=\mu_{0} \times \frac{N_{s p h} \times I_{n}}{2 \times e},
$$

Where $\mu 0$ is the air permeability, Nsph the stator winding number of turn and In is the rated current.

The thickness of the stator yoke and the thickness of the rotor yoke are calculated by applying the flow conservation theorem.

$$
\begin{aligned}
& H_{c s}=\frac{B_{d} \times S_{d}}{2 \times B_{c s} \times L_{m}}, \\
& H_{c r}=\frac{B_{e} \times S_{d}}{2 \times B_{c r} \times L_{m}},
\end{aligned}
$$

where Bd is the stator tooth flux density, $\mathrm{Sd}$ is the stator teeth section, Lm is the length of the active part of the stator, Bcs is the stator yoke flux density and Bcr is the rotor yoke flux density.

The height of the stator teeth can reserve space for the copper while taking account of the space occupied by the electrical insulator and the allowable current density in the copper.

$$
H_{d}=\frac{N_{s p h} \times I_{d i m}}{\delta \times L_{e n c} \times K_{f}},
$$

Where Idim is the dimensionning current, $\delta$ is the allowable current density in the copper, Lenc is the stator slot width and $\mathrm{Kf}$ the filling coefficient of the slots.

The winding resistance is calculated at a temperature of copper equal to $90^{\circ} \mathrm{C}$ considering an automated cooling system of the motor maintaining the temperature costant to this value.

$$
R\left(T_{c}\right)=\frac{\rho\left(T_{c}\right) \times N_{s p h} \times L_{s p}}{\frac{I_{d i m}}{\delta}},
$$

Where $\rho(T c)$ is the copper resistivity at a temperature equal to TC, Lsp is a winding turn length.

The phase's inductances of the motor are expressed by the following equations.

$$
\begin{gathered}
\text { if } 0 \leq \theta \leq A_{\text {dent } 1} ; \quad L_{1}=L_{c 0}+C_{i} \times \theta \\
\text { if } A_{\text {dent } 1} \leq \theta \leq 2 \times A_{\text {dent } 1 ;} \quad L_{1}=L_{c 0}+C_{i} \times A_{\text {dent } 1}-C_{i} \times \theta \\
\text { if } \frac{2}{3} \times 2 \times A_{\text {dent } 1} \leq \theta \leq \frac{7}{3} \times A_{\text {dent } 1} ; \quad L_{2}=L_{c 0}+C_{i} \times\left(\theta-\frac{2}{3} \times 2 \times A_{\text {dent } 1}\right) \\
\text { if } \frac{7}{3} \times A_{\text {dent } 1} \leq \theta \leq \frac{10}{3} \times A_{\text {dent } 1 ;} \quad L_{2}=L_{c 0}+C_{i} \times A_{\text {dent } 1}-C_{i} \times\left(\theta-\frac{7 \times A_{\text {dent } 1}}{3}\right), \\
\text { if } \frac{4}{3} \times 2 \times A_{\text {dent } 1} \leq \theta \leq \frac{11}{3} \times A_{\text {dent } 1} ; \quad L_{2}=L_{c 0}+C_{i} \times\left(\theta-\frac{4}{3} \times 2 \times A_{\text {dent } 1}\right) \\
\text { if } \frac{11}{3} \times A_{\text {dent } 1} \leq \theta \leq \frac{14}{3} \times A_{\text {dent } 1 ;} \quad L_{2}=L_{c 0}+C_{i} \times A_{\text {dent } 1}-C_{i} \times\left(\theta-\frac{11 \times A_{\text {dent } 1}}{2}\right),
\end{gathered}
$$

where:

$$
\begin{gathered}
C_{i}=\frac{N_{d s p}}{2} \times \frac{\left(\mu_{0} \times \frac{D_{s t}}{2} \times L_{m}\right) \times\left(\frac{N_{s p h}}{\left(\frac{N_{d s p}}{2}\right)}\right)^{2}}{2 \times e}, \\
L_{c l}=\frac{N_{d s p}}{2} \times \frac{\left(\mu_{0} \times H_{d} \times L_{m}\right) \times\left(\frac{N_{s p h}}{\left(\frac{N_{d s p}}{2}\right)}\right)^{2}}{L_{e n c}},
\end{gathered}
$$


The evolution of inductances according to the mechanical angle is illustrated in Figure 2.

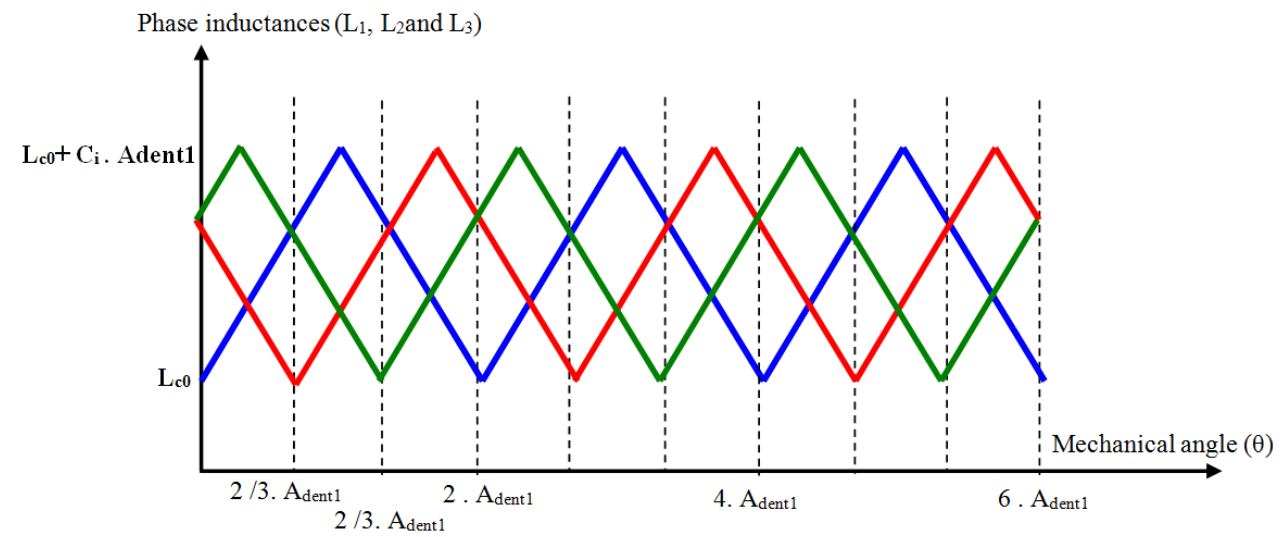

Figure 2. Evolution of the inductances in function of the mechanical angle.

$A_{\text {dent1 }}$ is the angular opening of a stator tooth, $\mu_{0}$ is the air absolute permeability, $\mathrm{N}_{\mathrm{sph}}$ is the phase number of turns, $\mathrm{N}_{\mathrm{dsp}}$ is the number of main teeth of the stator, $\mathrm{L}_{\mathrm{m}}$ is the engine length, $H_{d}$ is the height of a main stator tooth, $L_{e n c}$ is the slot width, $\mathrm{D}_{\mathrm{st}}$ is the bore diameter and $\theta$ is the rotor position.

\section{Control Strategy}

The speed of the electric car is regulated by a ProportionalIntegral-Derivative (PID) speed regulator type to minimize the error between the reference speed and response speed. Indeed, the regulator provides the amplitude of the reference currents to be adjusted to ensure continuous shapes generating a motor torque with little fluctuation by adding three adjustment loops for converting reference currents in ideal reference voltages modulated by a triangular signal to impose shapes of phase currents minimising car vibrations. This fact permit to supply the motor by two positive currents and one negative current. The sum of the three currents is equal to zero to have the current of the neutral wire equal to zero. The triangular shape of the motor phase inductance led us to apply the pulse width modulation technique with fixed switching frequency for reproducing the real shapes of the supply voltages produced by the DC-AC converter. This control strategy allows an interesting reduction in error between the response speed and the reference, which leads to a significant reduction of the mechanical vibrations of the studied transport system [3-26].

\section{Control Model}

\subsection{Simulink Model of the Inductances}

The Simulink model of inductances is shown in Figure 3.

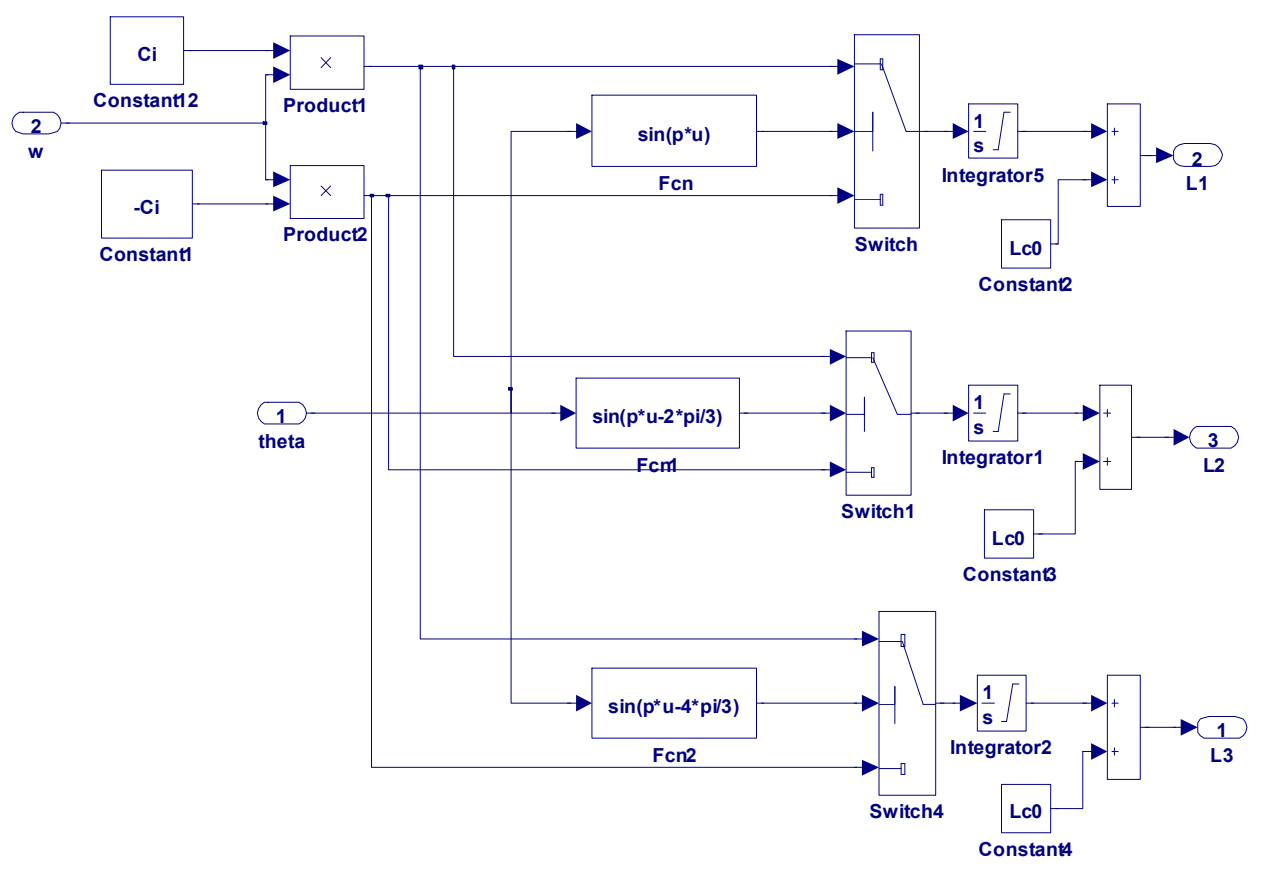

Figure 3. Simulink model of inductances. 


\subsection{Motor Model}

The motor phase's voltages are expressed by the following relationships.

$$
\begin{gathered}
V_{1}=R \times i_{1}+\frac{d\left(L_{1} \times i_{1}\right)}{d t}, \\
V_{2}=R \times i_{2}+\frac{d\left(L_{2} \times i_{2}\right)}{d t}, \\
V_{3}=R \times i_{3}+\frac{d\left(L_{3} \times i_{3}\right)}{d t},
\end{gathered}
$$

where $\mathrm{R}$ is the phase resistance, L1, L2and L3are respectively the inductance of the phase 1,2 and 3and i1, i2and i3are respectively the current of the phase 1, 2 and 3 .
The resistance is calculated for a temperature value equal to $90^{\circ} \mathrm{C}$, considering an integrated cooling system automated to maintainingthe temperature of copper constant equal to this value.

The torque developed by the motor is expressed by the following relationship.

$$
T_{m}=\frac{1}{\Omega} \frac{d\left(\frac{1}{2} \times\left(L_{1} \times i_{1}^{2}+L_{2} \times i_{2}^{2}+L_{3} \times i_{3}^{2}\right)\right)}{d t},
$$

The electrical-mechanical motor model is implanted under the simulation environment Matlab-Simulink according to Figure 4.

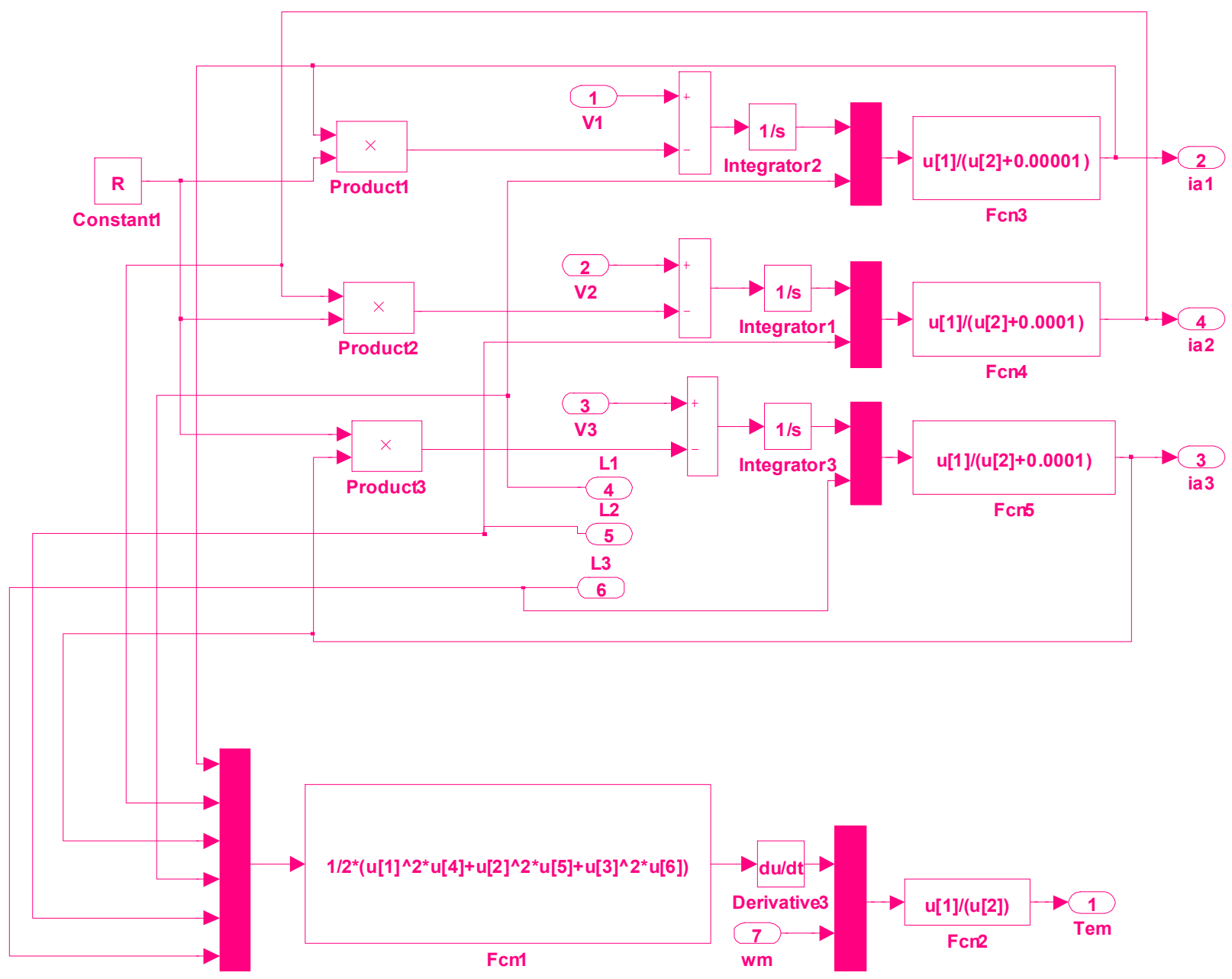

Figure 4. Electrical-mechanical simulink model of the motor.

\subsection{Speed Regulator}

A Proportional-Integral-Derivative (PID) regulator type is used to provide the amplitude of references current minimizing the error between the reference and the response speeds. This control structure makes it possible the reduction of the response speed fluctuation since the wide variation of inductance leads a significant torque ripple produced by the engine. The speed controller parameters are calculated by the Genetic Algorithms methodto minimize torque ripple and reduce thereafter the fluctuation of the response speed [1626].

The Simulink model of the speed controller is shown in Figure 5. 


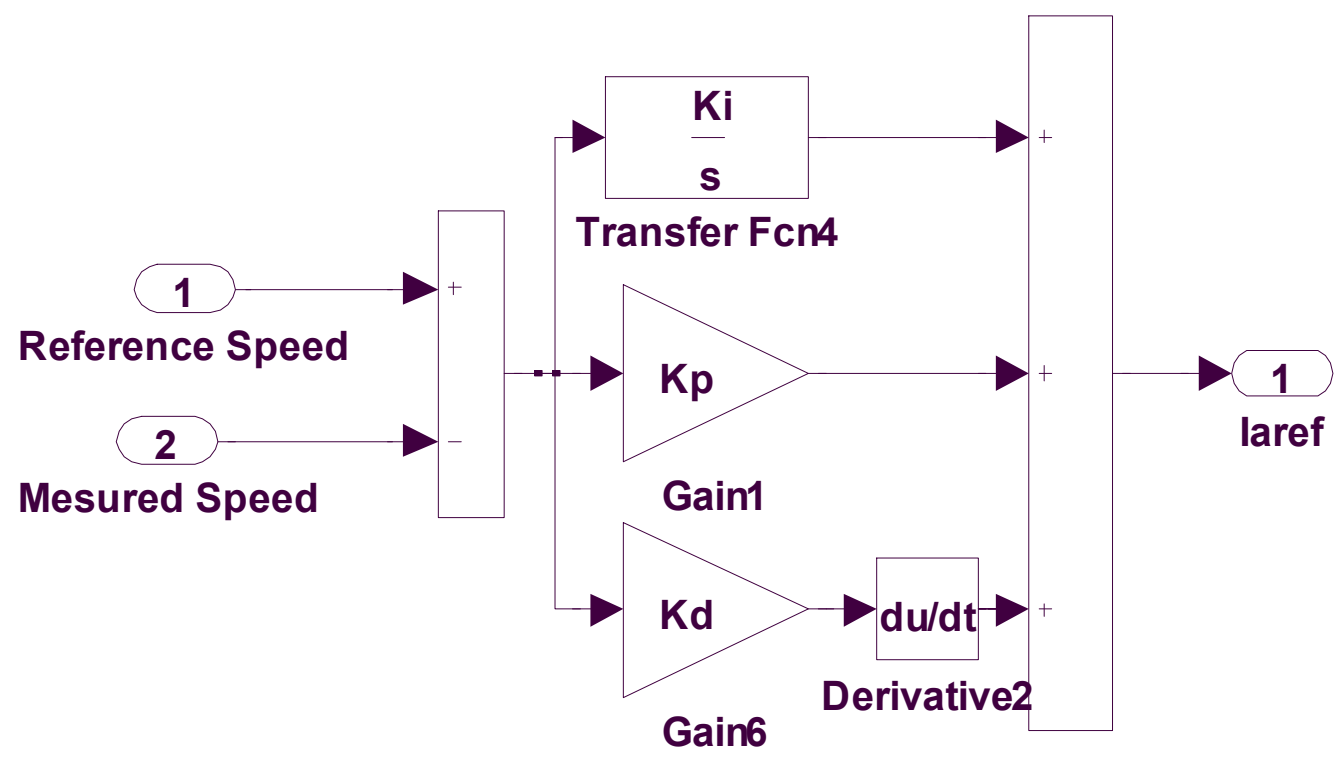

Figure 5. Simulink model of the speed controller.

\subsection{Currents Regulators}

Current regulators are used to adjust the amplitude and shape of currents minimizing the fluctuation of the torque to minimize the error between the reference and the response speeds. Currents can be decomposed into a DC component and a component varying in phase opposition with the inductances. For a constant reference speed, two currents are positives and the other is negative to have an optimized shape of the motor torque. Errors between the measured and the reference currents attack two proportional-integral-derivative regulators type to provide the two reference voltages required for generating the two control signals of the IGBT transistors. Current Regulators parameters are calculated by the Genetic Algorithms method to minimize torque ripple and reduce thereafter the fluctuation of the response speed [16-26].

The Simulink model of the current regulators is illustrated in Figure 6.

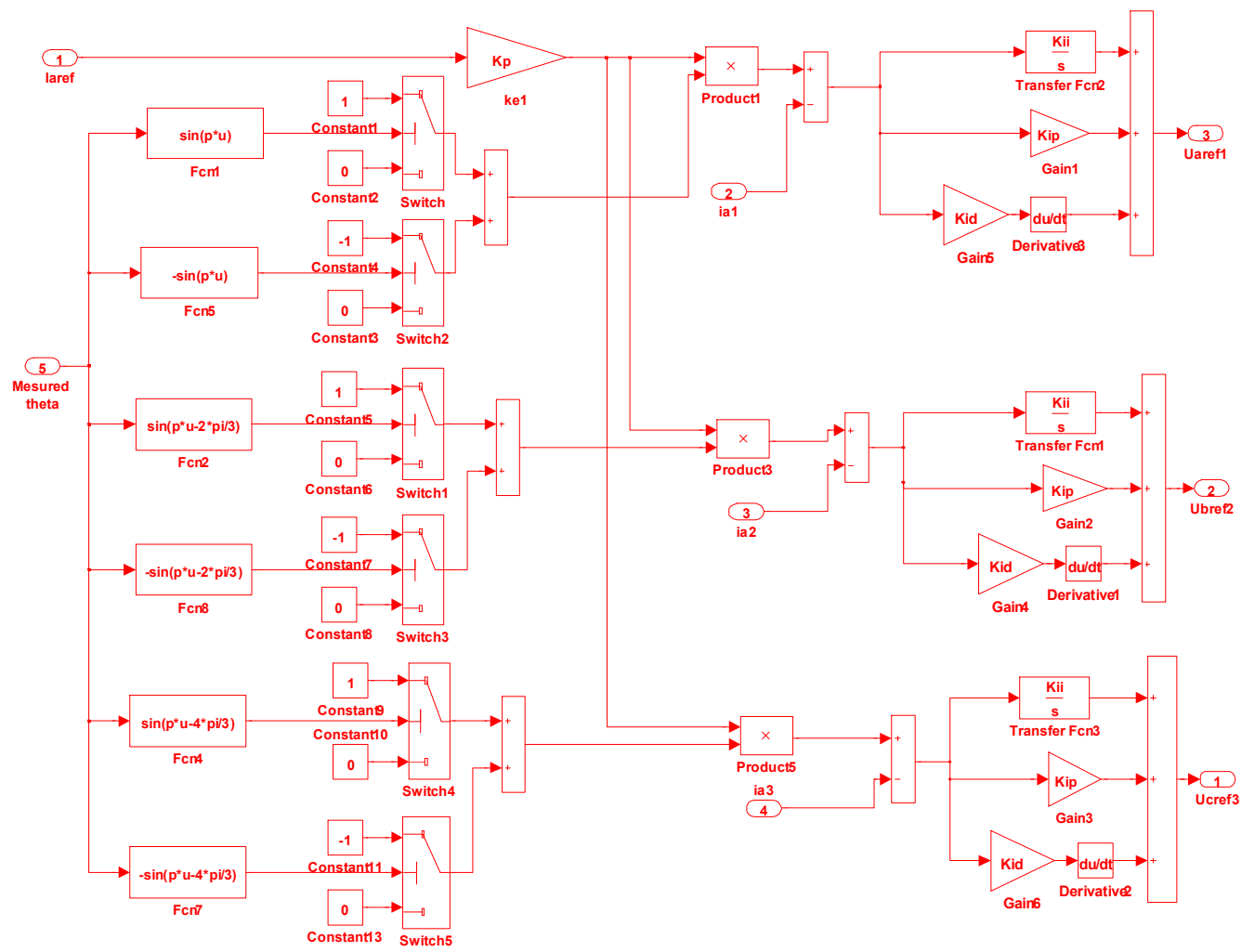

Figure 6. Simulink model of the current regulators. 


\subsection{Converter Model}

The structure of the converter supplying the two motor windings is shown in Figure 7 [16-26].

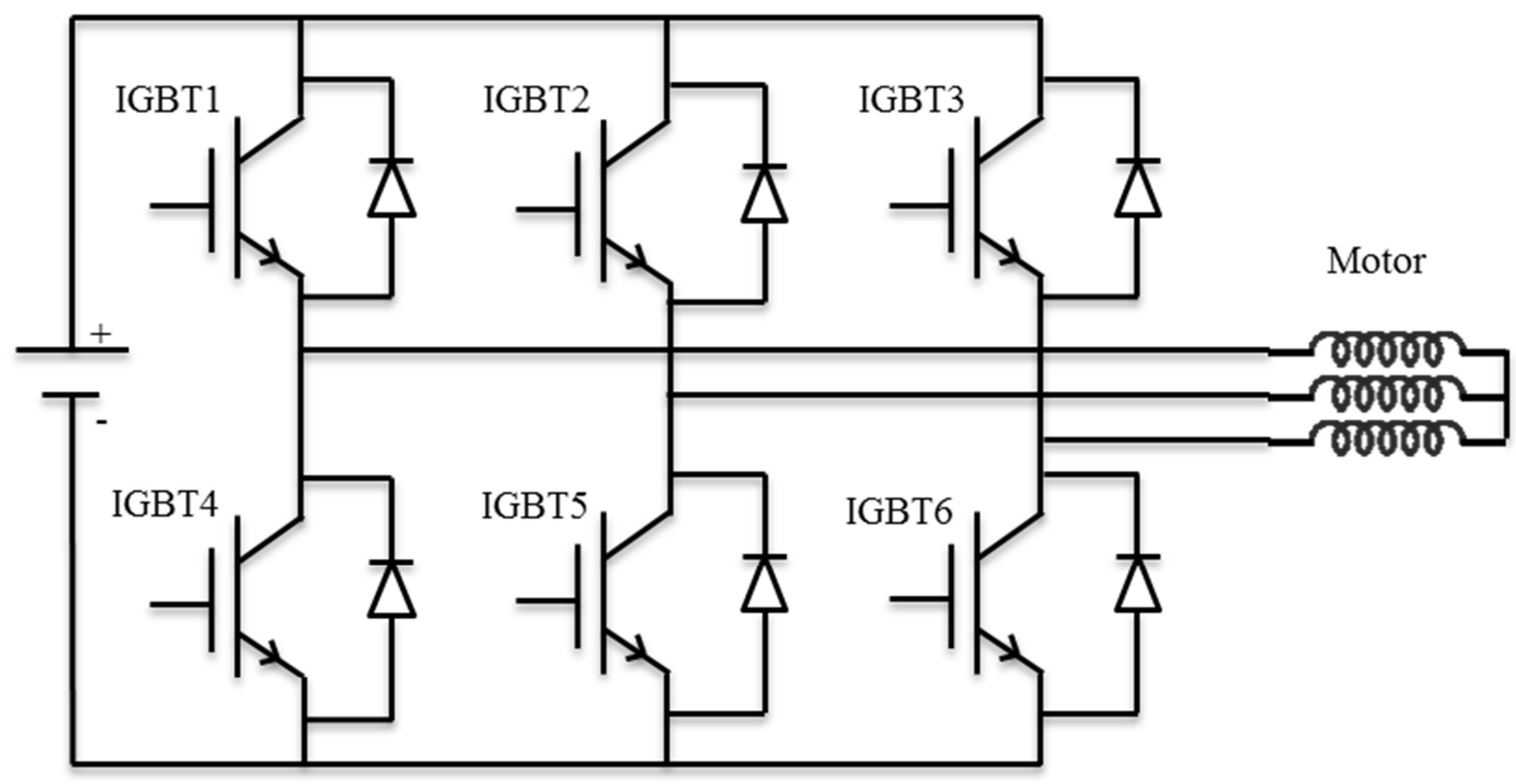

Figure 7. Structure of the converter supplying the two motor windings.

The approximated model of the converter is based on the modulation of the three reference voltages by a triangular signal. The outputs of the three comparators attack two hysteresis varying from the value of the DC bus voltage Udc and 0 to reproduce the evolution of the three phases supply voltages.

The Simulink model of the converter is shown in Figure 8.

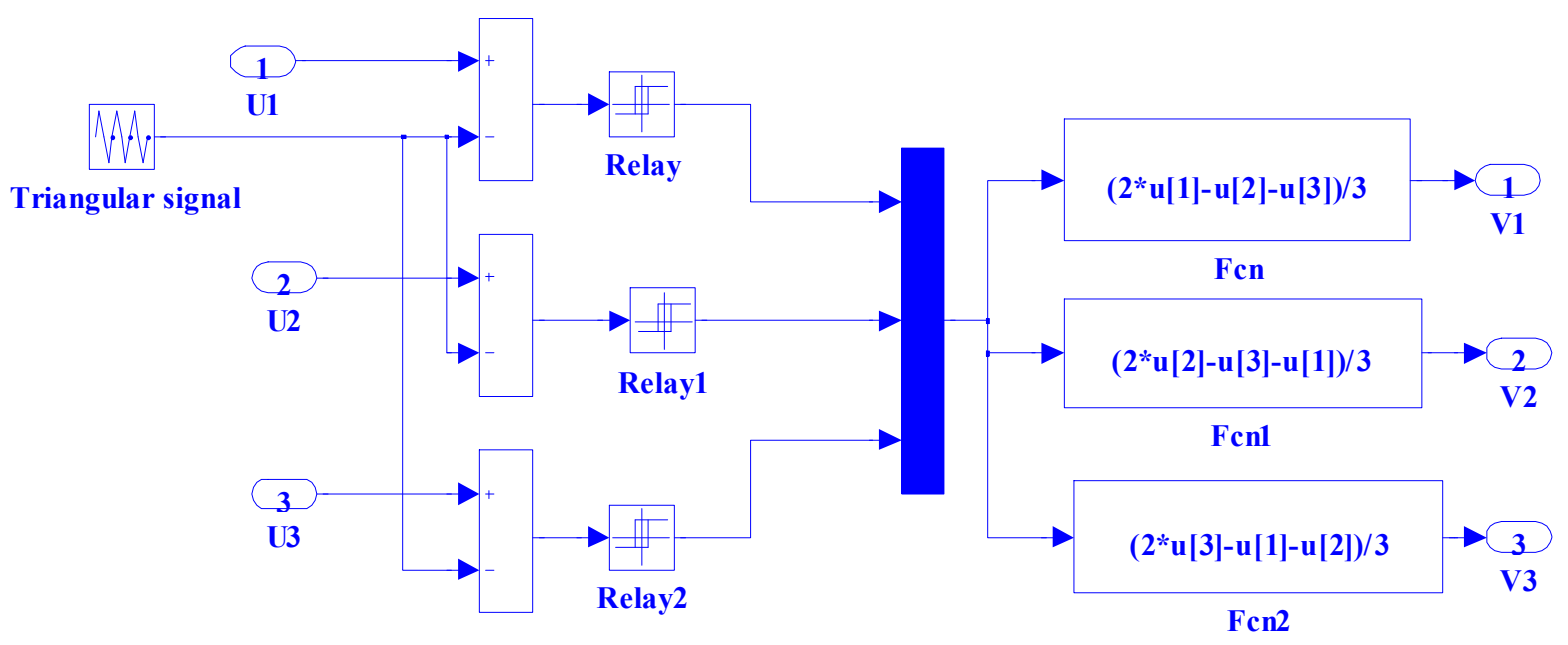

Figure 8. Simulink model of the converter.

\subsection{Motion Equation}

The electric car motion equation is derived from the fundamental relationship of dynamics.

$$
M_{v} \times R_{\text {roue }} \times \frac{d V}{d t}=r \times T_{m}-T_{R}(V),
$$

Where $M_{v}$ is the electric car mass, $R_{\text {roue }}$ is the radius of a wheel, $V$ electric car speed, $T_{m}=T_{e m}$ is the motor developed torque, $r$ gear ratio and $T_{R}$ is the load torque.

The equation of motion is implanted under the simulation environment Matlab-Simulink according to Figure 9 [3-26]. 


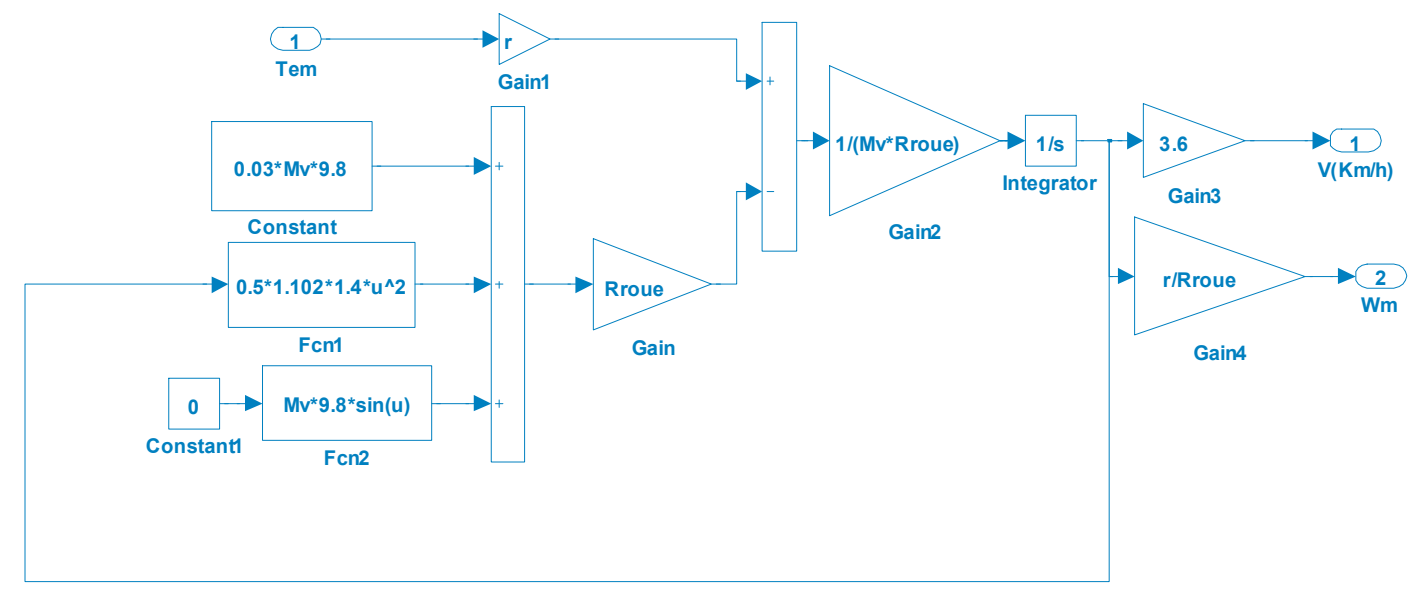

Figure 9. Simulink model of the motion equation.

\subsection{Power Chain Global Model}

The coupling of the different models of the power chain leads to the global model implanted under the simulation environment Matlab-Simulink according to Figure 10.

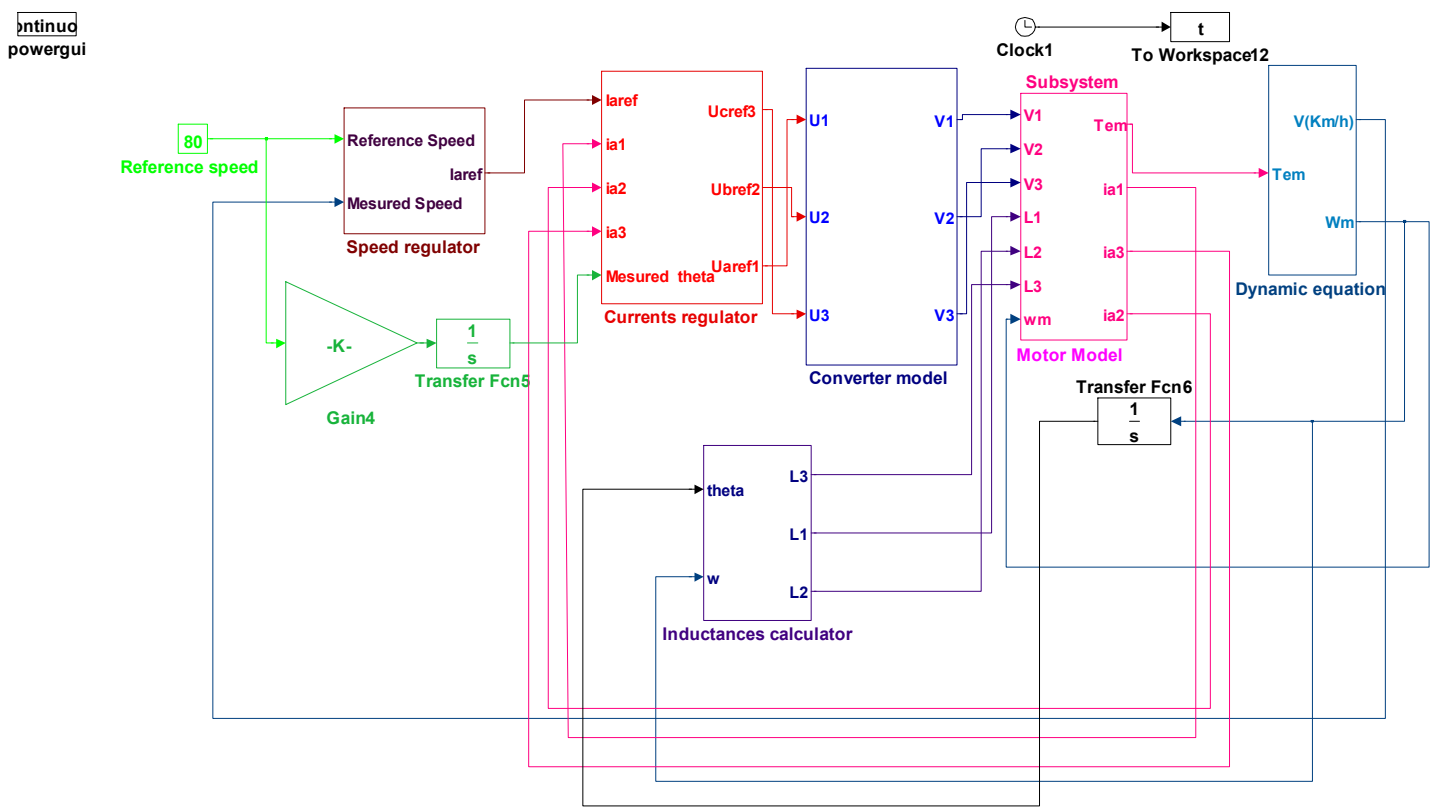

Figure10. Globalmodelofthepowerchain.

\section{Simulations Results Descriptions}

The simulation parameters (Table 1) are calculated from the design and modelling program of the studied switching synchronous motor.

Table 1. Simulation parameters.

\begin{tabular}{lll}
\hline Parameters & Values & Units \\
\hline Ratiobetweenthemechanicalangleandtheelectricangle $(\mathrm{p})$ & 4 & $/$ \\
Phaseresistance $(\mathrm{R})$ & $0.09110^{-3}$ & $\Omega$ \\
DCbusvoltage $(\mathrm{Udc})$ & 17 & Volt \\
Gearratio(r) & 3 & $/$ \\
Minimalvalueoftheinductance $\left(\mathrm{L}_{\mathrm{c} 0}\right)$ & $0.18810^{-3}$ & $\mathrm{H}$ \\
Inductanceconstant $\left(\mathrm{C}_{\mathrm{i}}\right)$ & $0.06310^{-3}$ & $\mathrm{H} / \mathrm{rad}$ \\
Switchingfrequency $\left(\mathrm{f}_{\mathrm{sw}}\right)$ & 20 & $\mathrm{~Hz}$ \\
\hline
\end{tabular}

The response speed to a reference speed equal to $80 \mathrm{~km} / \mathrm{h}$ is shown in Figure 11. From this figure, it can be concluded that the speed fluctuations are greatly reduced, thus confirming the performance of the control algorithm developed also the validity of the design program.

The phase current change is shown in Figure 12. The figure 12 shows that the underground starts with reduced current values, which demonstrates the effectiveness of the method of calculation of the speed controller and the current regulators parameters. The current steady state phases are continuous fluctuating between significant values, which is explained by the high salience of the engine [16-25].

Figure 13 shows the evolution in function of the time of phase inductances. This figure shows that these inductances are the sum of a constant value relative to the leakage 
inductance and a value varying linearly relative to the inductance of motor saliency. The inductances are shifted the one related to the second and the second related to the third by an angle equal to $2 . \pi / 3$.

Gaits over time of the voltage and current of phase 1, phase 2 and phase 3 are illustrated in Figure 14. The figure 14 shows that the current has a large variation which causes a symmetrical variation of the electromagnetic torque. The effect of this variation is reduced by the large electric car inertia and the right choice of speed and currents regulators parameters.

Figure 15 illustrates the evolution of the torque developed by the motor over time. The Figure 15 shows that the torque passes symmetrically to negative values adjusted so as to minimize the fluctuation in the steady state response speed while taking into account the strong inertia of the car. In addition, the high value of inertia favors the advantages of the possibility to maintaining the speed of the electric car constant with little fluctuation.

Finally, simulation results showing the effectiveness of the switching motor control algorithm minimizing vibration, and fully valid the dimensioning and modelling approach of the switching motor.

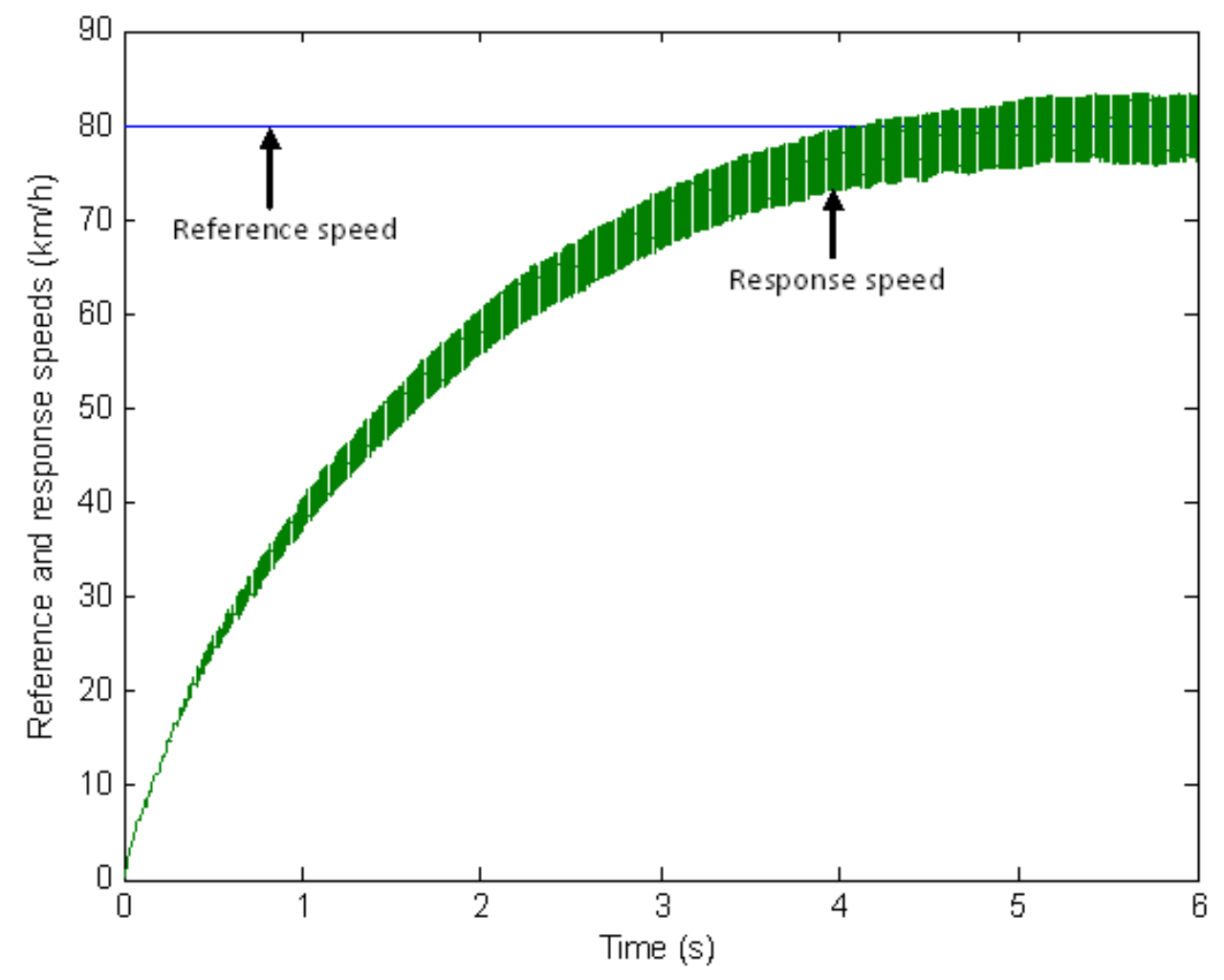

Figure 11. Response speed to a reference speed equal to $80 \mathrm{~km} / \mathrm{h}$.

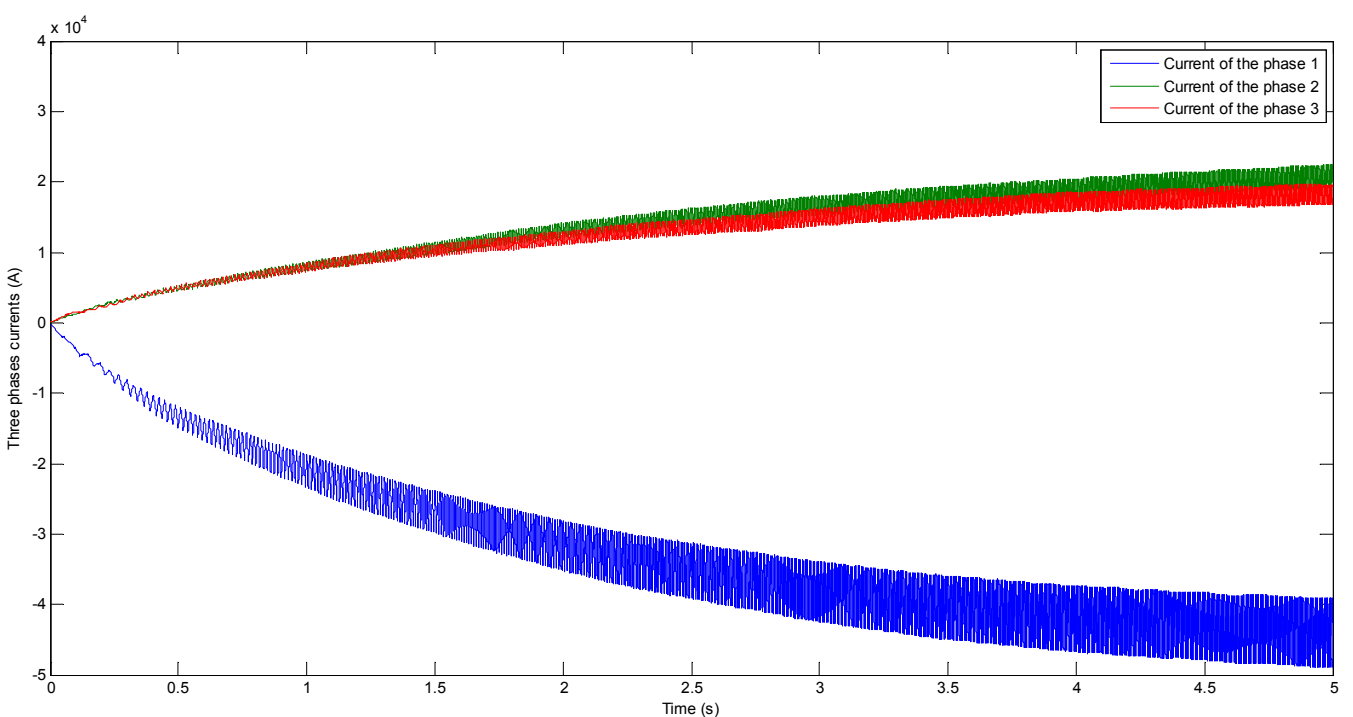

a. Evolution from $0 \mathrm{~s}$ to $5 \mathrm{~s}$ of the three phase current 


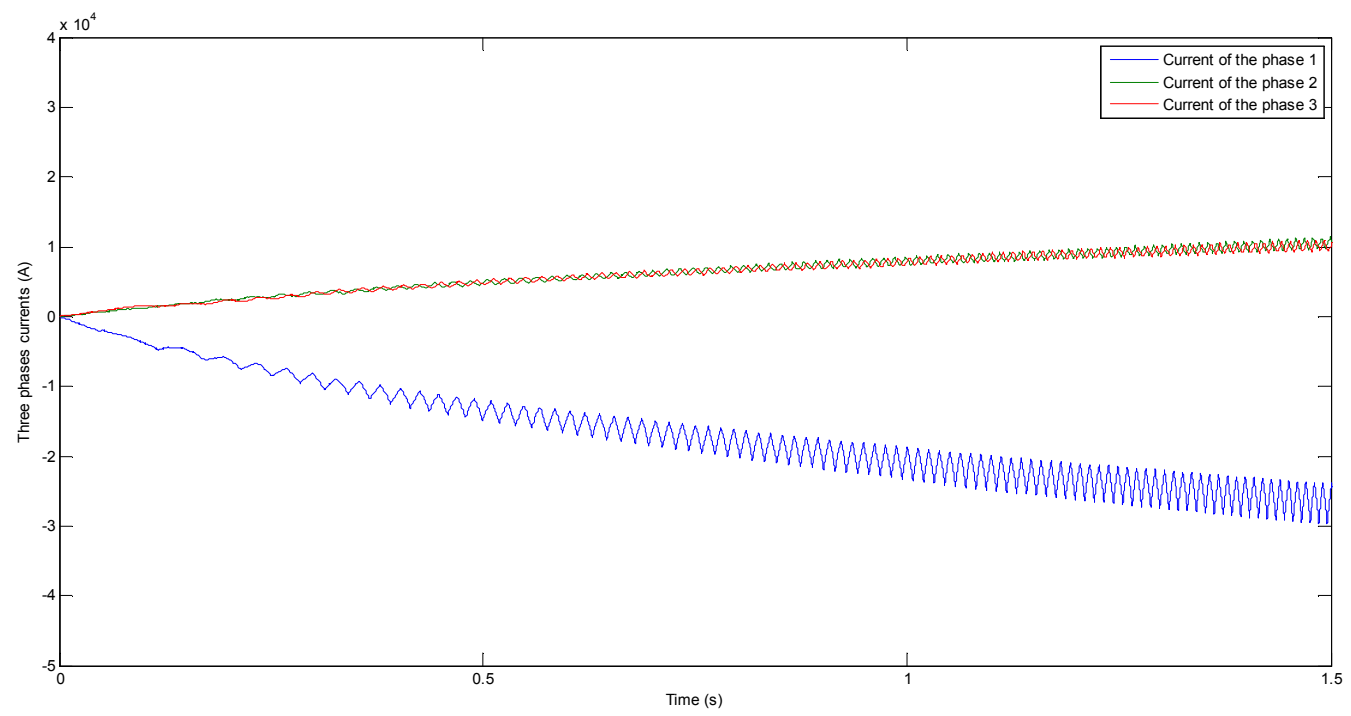

b. Zoom of the evolution of the three phase currents

Figure 12. Evolution of the phase currents.

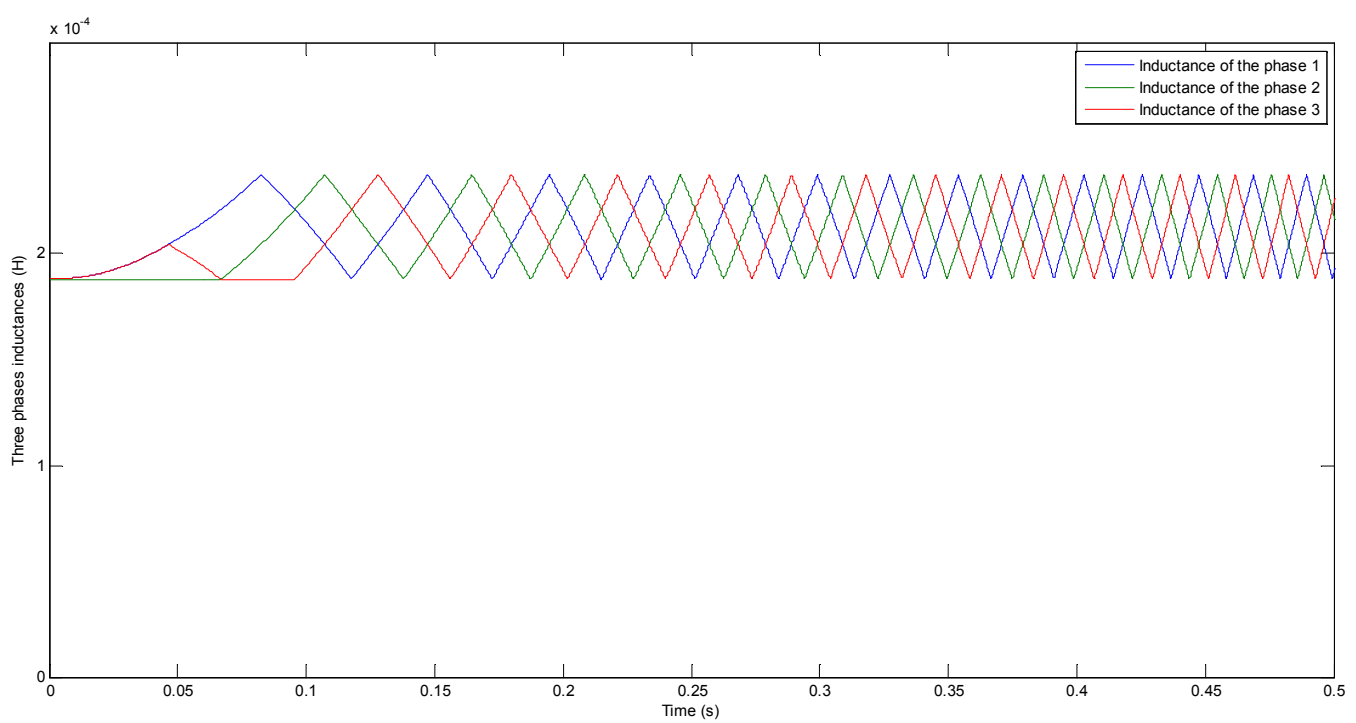

Figure 13. Evolution of the phase inductances in function of the time.
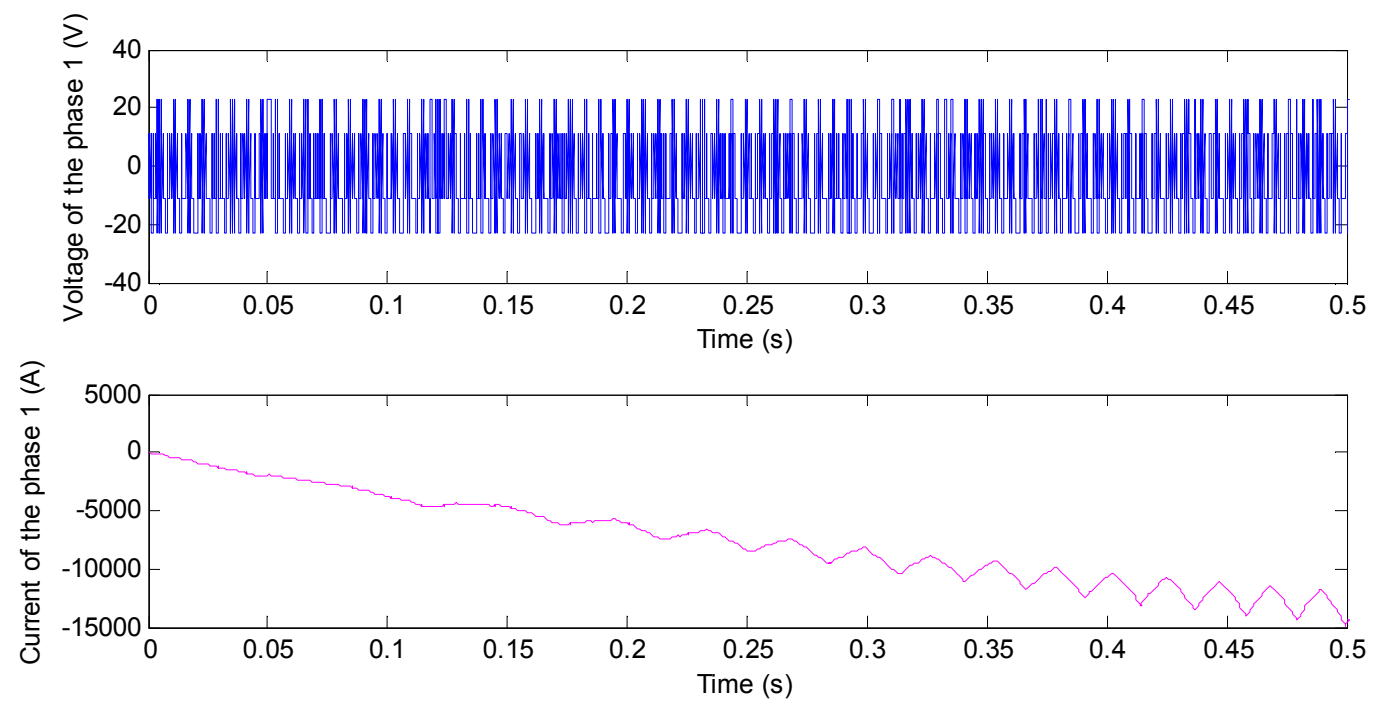

a. Voltage and current of the phase 1 

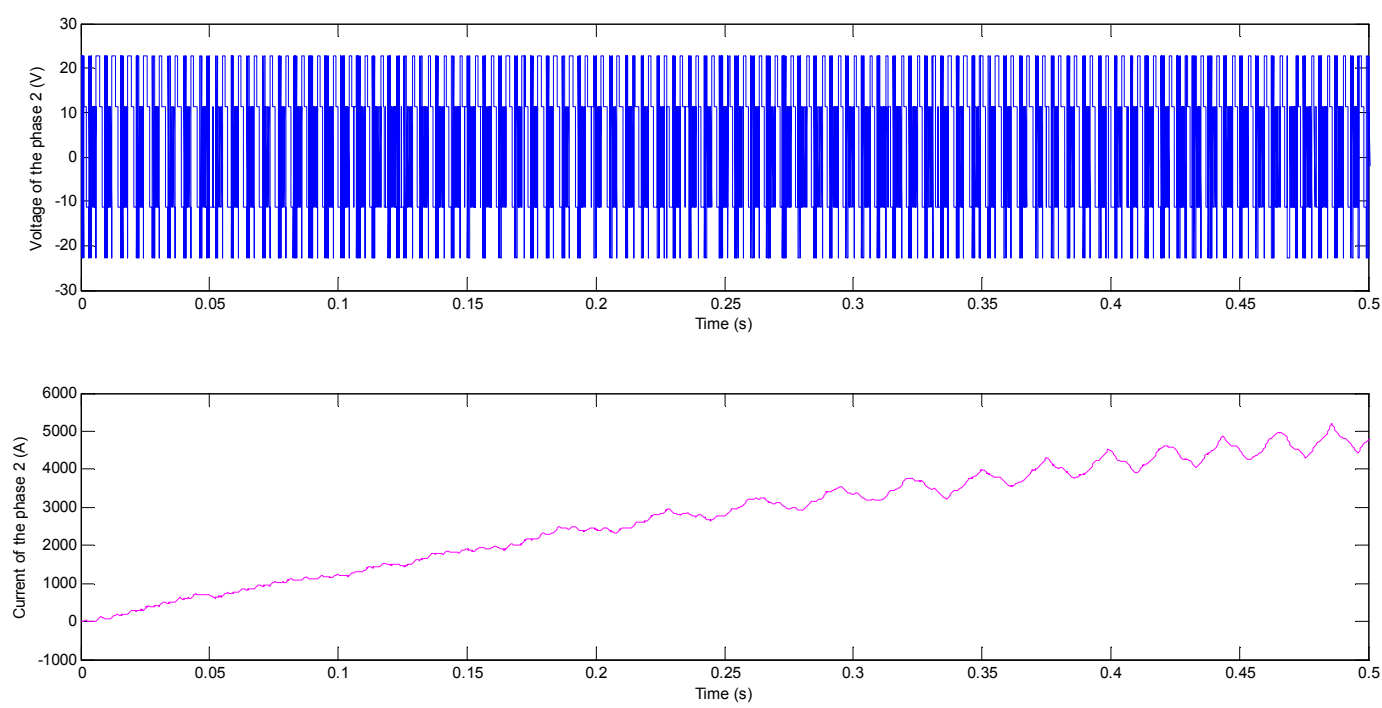

b. Voltage and current of the phase 2
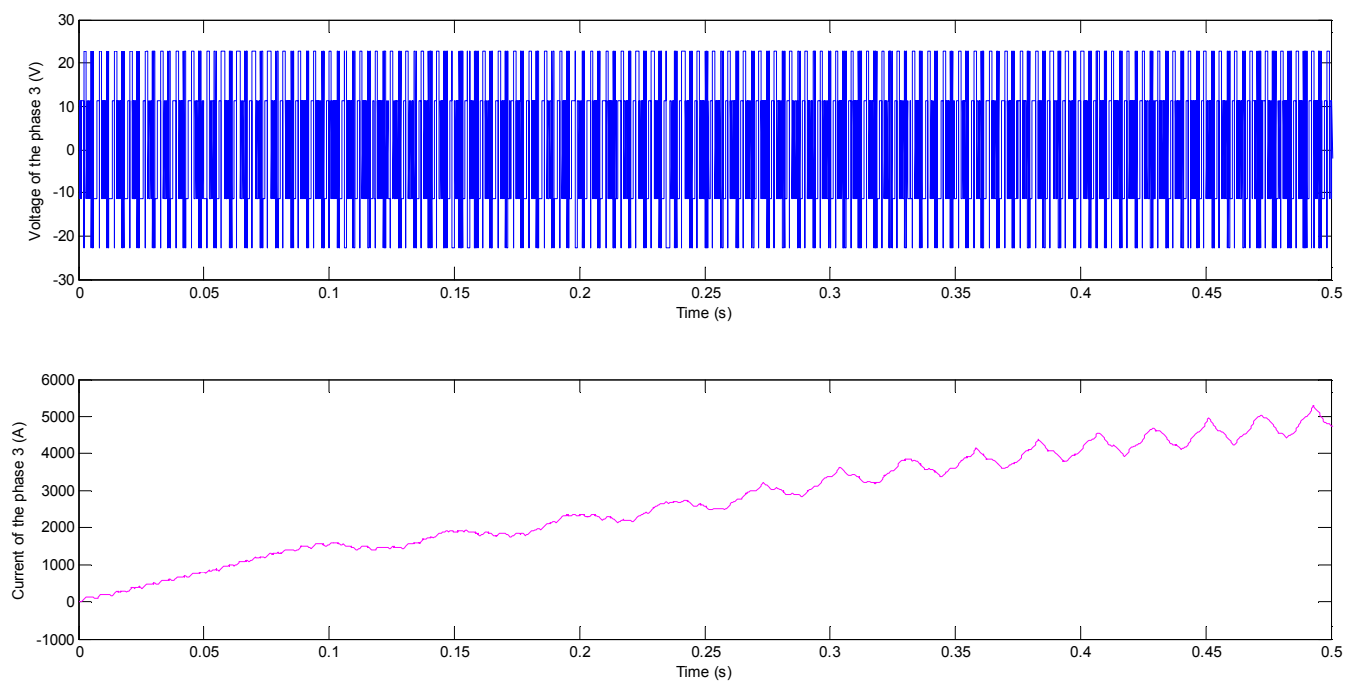

c. Voltage and current of the phase 3

Figure 14. Gaits over time of the voltage and current of the three phases.
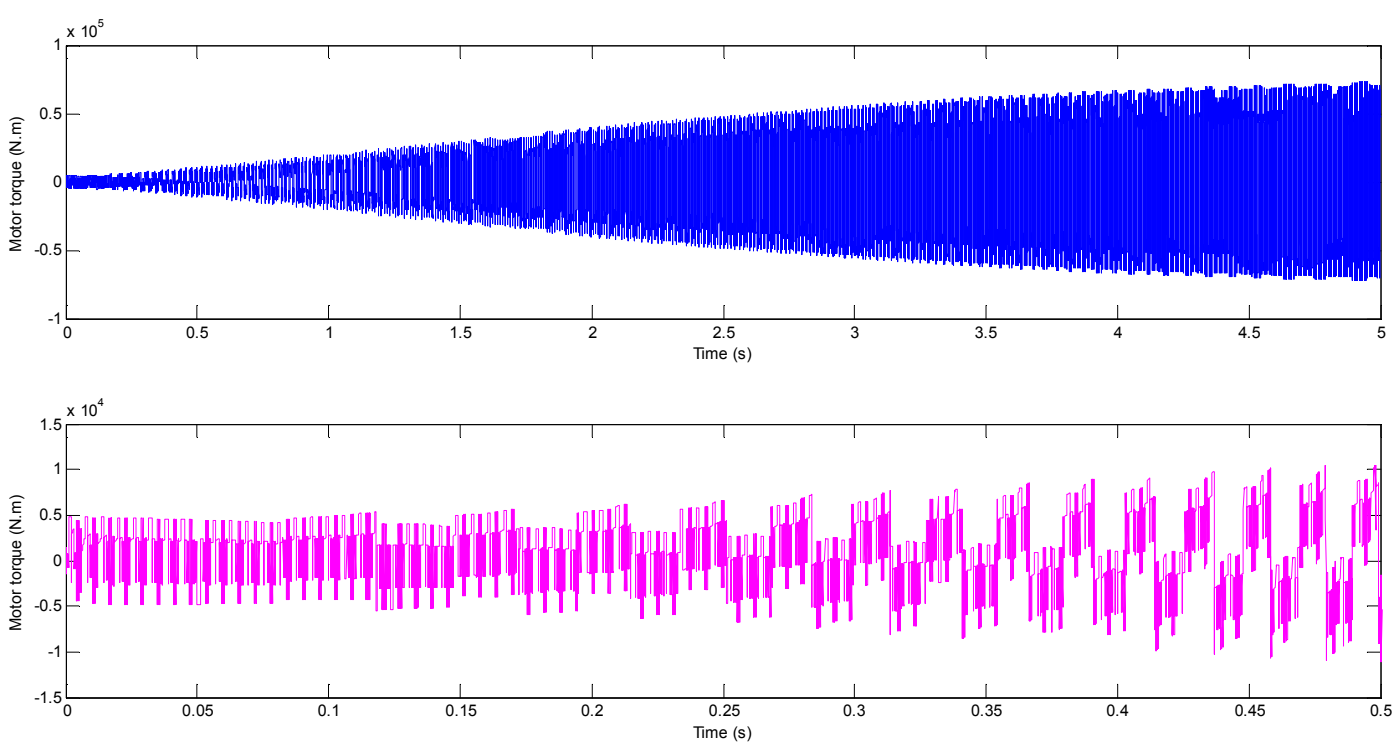

Figure 15. Evolution of the motor torque in function of the time. 


\section{Conclusion}

In this paper, we presented a control algorithm of an innovated structure of switching synchronous motor. This algorithm is suitable for the design and modelling program of the engine dedicated to electric car motorization. Simulation results are with good standard and entirely valid dimensioning program and the control algorithm. As perspective, it will be interesting to industrialize the overall studied system.

\section{References}

[1] X. D. Xue, K. W. E. Cheng, and N. C Cheung, "Selection of electric motor drives for electric vehicles," in Australasian Universities Power Engineering Conference, 2008, pp. 1-6.

[2] X. D. Xue, K. W. E. Cheng, T. W. Ng, and N. C. Cheung, "Multiobjective optimization design of inwheel switched reluctance motors in electric vehicles," IEEE Transactions on industrial electronics, vol. 57, no. 9, pp. 2980-2987, Septembre 2010.

[3] Saber HADJ ABDALLAH and Souhir TOUNSI : «OPTIMAL DESIGN AND CONTROL OF ELECTRIC VEHICLE POWER CHAIN» Journal of Electrical Engineering (JEE), Volume 15, 2015, Edition 3, pp. 294-304, Indexed in SCOPUS

[4] Ajmia BEGACEM, Mohamed Amine FAKHFAKH and Souhir TOUNSI: «OPTIMAL DESIGN AND CONTROL OF ELECTRIC VEHICLE POWER CHAIN» Journal of Electrical Engineering (JEE), Volume 15, 2015, Edition 2, pp. 294-304, Indexed in SCOPUS.

[5] P. J. Lawrenson, J. M. Stephenson, P. T. Blenkinsop, J. Corda, and N. N. Fulton, "Variable-speed switched reluctance motors," IEE Proccedings, vol. 127, no. 4, pp. 253-265, July 1980.

[6] Souhir Tounsi, Robust Design and Control of Linear Actuator Dedicated to Stamping Press Application, International Journal of Electrical Components and Energy Conversion. Vol. 1, No. 5, 2015, pp. 92-101. doi: 10.11648/j.ijecec.20150105.11.

[7] Souhir Tounsi, Trapezoidal Control Integrating the Losses of an Electric Car Power Train, International Journal of Electrical Components and Energy Conversion. Vol. 1, No. 4, 2015, pp. 83-91. doi: 10.11648/j.ijecec.20150104.11.

[8] Souhir Tounsi, Modelling of a Generation System with Coiled Rotor Synchronous Generator for Renewable Energy, International Journal of Electrical Components and Energy Conversion. Vol. 1, No. 3, 2015, pp. 75-82. doi: 10.11648/j.ijecec.20150103.12.

[9] Souhir Tounsi, Comparative Study between the Synchronous Motor to Permanent Magnets and Axial Flux (MSAP) and its Equivalent to Coiled Rotor (MSRB), International Journal of Electrical Components and Energy Conversion. Vol. 1, No. 3, 2015, pp. 69-74. doi: 10.11648/j.ijecec.20150103.11.

[10] Souhir Tounsi, Electro-thermal Modeling of Permanent Magnet Synchronous Motor, International Journal of Electrical Components and Energy Conversion. Vol. 1, No. 2, 2015, pp. 63-68. doi: 10.11648/j.ijecec.20150102.13.
[11] Zaineb Gorbel, Yamina Chihaoui, Nader Barg, Mounir Yahyaoui, Souhir Tounsi, Modelling Approach of Electric Cars Autonomy, International Journal of Electrical Components and Energy Conversion. Vol. 1, No. 2, 2015, pp. 55-62. doi: 10.11648/j.ijecec.20150102.12.

[12] Moez Hadj Kacem, Souhir Tounsi, Rafik Neji, Losses Modeling of the Electric Vehicles Power Chain, International Journal of Electrical Components and Energy Conversion. Vol. 1, No. 2, 2015, pp. 49-54. doi: 10.11648/j.ijecec.20150102.11.

[13] Marwa Sellami, Souhir Tounsi, Control of Axial Flux DC Motor with Permanent Magnet Dedicated to Electric Traction, International Journal of Electrical Components and Energy Conversion. Vol. 1, No. 1, 2015, pp. 44-48. doi: 10.11648/j.ijecec.20150101.15.

[14] Amal Suilah, Nadia Graja, Amal Boudaya, Souhir Tounsi, Modelling of Synchronous Generation System for Renewable Energy, International Journal of Electrical Components and Energy Conversion. Vol. 1, No. 1, 2015, pp. 36-43. doi: 10.11648/j.ijecec.20150101.14.

[15] Mariem Ben Amor, Ajmia Belgacem, Souhir Tounsi, Optimal Design and Control of Electric Vehicles Power Chain with Electromagnetic Switch, International Journal of Electrical Components and Energy Conversion. Vol. 1, No. 1, 2015, pp. 24-35. doi: 10.11648/j.ijecec.20150101.13.

[16] M. C. Costa et al., "Optimisation of a switched reluctance motor using experimental design method and diffuse elements response surface," in IEE Proceedings- Science, Measurement and Technology, 2005, pp. 411-413.

[17] Iqbal Husein, "Minimization of torque ripple in SRM drives," IEEE Transactions on Industrial Electronics, vol. 49, no. 1, pp. 28-39, Février 2002.

[18] Arthur Radun, "Analytically computing the flux linked by a switched reluctance motor phase when the stator and rotor poles overlap," IEEE Transactions on magnetics, vol. 36, no. 4, pp. 1996- 2003, Juliet 2000.

[19] Arthur Radun, "Analytical calculation of the switched reluctance motor's unaligned inductance," IEEE Transaction on Magnetics, vol. 35, no. 6, pp. 4473-4481, Novembre 1999.

[20] Seok-Myeong Jang, Dae-Joon You, Young-Hee Han, and Jeong-Phil Lee, "Analytical design and dynamic characteristics of switched reluctance motors with minimum torque ripple," in Proceeding of International Conference on Electrical Machines and Systems, Seoul, Korea, 2007, pp. 1236-1239.

[21] Guiying Song, Zhida Li, Zhenghan Zhao, and Xiang Wang, "Direct Torque Control of Switched Reluctance Motors," in International Conference on Electrical Machines and Systems ICEMS 2008, Wuhan, 2009, pp. 3389-3392.

[22] Hai-Jiao Guo, "Considerations of Direct Torque Control for Switched Reluctance Motors," in IEEE International Symposium on Industrial Electronics, Montreal, 2006, pp. 2321-2325.

[23] Akitomo Komatsuzaki, Yojiro Miura, and Ichiro Miki, "Novel Position Estimation for Switched Reluctance Motor Based on Space Vector of Phase Inductance," in International Conference on Electrical Machines and Systems ICEMS, Wuhan, 2008, pp. 2932-2937. 
[24] Mitani Mitani, Hiroki Goto, Hai-Jiao Guo, and Osamu Ichinokura, "Position Sensorless Direct Torque Control of SR Motors," in EPE-PEMC, Portoroz, 2006, pp. 1143-1148.

[25] Yong-Ho Yoon, Jae-Moon Kim, Chung-Yuen Won, and Lee Byoung-Kuk, "New approach to SRM drive with six-switch converter," Mechatronics, pp. 1-13, 2009.
[26] R. NEJI, S. TOUNSI et F. SELLAMI: Contribution to the definition of a permanent magnet motor with reduced production cost for the electrical vehicle propulsion, European Transactions on Electrical Power (ETEP), 2006, 16: pp. 437460. 